\title{
Altered Hippocampal White Matter Connectivity in Type 2 Diabetes Mellitus and Memory Decrements
}

Citation for published version (APA):

van Bussel, F. C. G., Backes, W. H., Hofman, P. A. M., van Boxtel, M. P. J., Schram, M. T., Stehouwer, C. D. A., Wildberger, J. E., \& Jansen, J. F. A. (2016). Altered Hippocampal White Matter Connectivity in Type 2 Diabetes Mellitus and Memory Decrements. Journal of Neuroendocrinology, 28(3), [12366]. https://doi.org/10.1111/jne.12366

Document status and date:

Published: 01/03/2016

DOI:

10.1111/jne.12366

Document Version:

Publisher's PDF, also known as Version of record

Document license:

Taverne

Please check the document version of this publication:

- A submitted manuscript is the version of the article upon submission and before peer-review. There can be important differences between the submitted version and the official published version of record.

People interested in the research are advised to contact the author for the final version of the publication, or visit the DOI to the publisher's website.

- The final author version and the galley proof are versions of the publication after peer review.

- The final published version features the final layout of the paper including the volume, issue and page numbers.

Link to publication

\footnotetext{
General rights rights.

- You may freely distribute the URL identifying the publication in the public portal. please follow below link for the End User Agreement:

www.umlib.nl/taverne-license

Take down policy

If you believe that this document breaches copyright please contact us at:

repository@maastrichtuniversity.nl

providing details and we will investigate your claim.
}

Copyright and moral rights for the publications made accessible in the public portal are retained by the authors and/or other copyright owners and it is a condition of accessing publications that users recognise and abide by the legal requirements associated with these

- Users may download and print one copy of any publication from the public portal for the purpose of private study or research.

- You may not further distribute the material or use it for any profit-making activity or commercial gain

If the publication is distributed under the terms of Article $25 \mathrm{fa}$ of the Dutch Copyright Act, indicated by the "Taverne" license above, 


\title{
Altered Hippocampal White Matter Connectivity in Type 2 Diabetes Mellitus and Memory Decrements
}

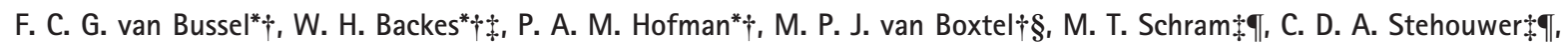

J. E. Wildberger*t and J. F. A. Jansen* ${ }^{*}$

*Department of Radiology \& Nuclear Medicine, Maastricht University Medical Center, Maastricht, The Netherlands.

$\dagger$ School for Mental Health and Neuroscience (MHeNS), Maastricht University Medical Center, Maastricht, The Netherlands.

\$Cardiovascular Research Institute Maastricht (CARIM), Maastricht University Medical Center, Maastricht, The Netherlands. §epartment of Psychiatry and Neuropsychology, Maastricht University Medical Center, Maastricht, The Netherlands.

IDepartment of Internal Medicine, Maastricht University Medical Center, Maastricht, The Netherlands.

\section{Journal of Neuroendocrinology}

Correspondence to: $\operatorname{Dr}$ J. F. A. Jansen, Department of Radiology \& Nuclear Medicine, Maastricht University Medical Center, PO Box 5800, 6202 AZ Maastricht, The Netherlands (e-mail: jacobus.jansen@mumc.nl).
Type 2 diabetes mellitus is associated with cognitive decrements. Specifically affected cognitive domains are learning and memory, for which the hippocampus plays an essential role. The pathophysiological mechanism remains to be revealed. The present study examined whether local hippocampal microstructure and white matter connectivity are related to type 2 diabetes and memory performance. Forty participants with type 2 diabetes and 38 participants without type 2 diabetes underwent detailed cognitive assessment and 3-Tesla diffusion magnetic resonance imaging (MRI). Diffusion MRI was performed to assess microstructure (fractional anisotropy and mean diffusivity) and white matter connectivity (tract volume) of the hippocampus, which were compared between participants with and without type 2 diabetes. No differences in hippocampal microstructure were observed. Participants with type 2 diabetes had fewer white matter connections between the hippocampus and frontal lobe $(P=0.017)$. Participants who scored lower on memory function, regardless of type 2 diabetes, had fewer white matter connections between the hippocampus and temporal lobe $(P=0.017)$. Taken together, type 2 diabetes and memory decrements appear to be associated with altered hippocampal white matter connectivity.

Key words: cognition, memory, diffusion, white matter connectivity, hippocampus

doi: $10.1111 /$ jne. 12366
Type 2 diabetes mellitus is associated with cognitive decrements (1), accelerated cognitive decline (2) and an increased risk for developing dementia and Alzheimer's disease (2-5). In particular, learning and memory are the most prominently and specifically affected cognitive domains $(6,7)$. It is well known that the hippocampus plays an essential role in learning and memory processes. Previous studies, which focused on conventional structural magnetic resonance imaging (MRI), demonstrated hippocampal atrophy in type 2 diabetes patients with memory problems (8-10). Using functional MRI, Zhou et al. (11) showed reduced functional connectivity between the hippocampus and other parts (i.e. frontal, temporal and parietal) of the brain. Therefore, there is a need to investigate whether the intrinsic hippocampal microstructure and the white matter connectivity to other brain regions are affected in type 2 diabetes and related to memory decrements.
Diffusion MRI (dMRI) is a non-invasive advanced MRI technique that provides greater insights into cerebral white matter abnormalities (i.e. microstructure and white matter connectivity) by measuring the hindered diffusion of water molecules. The most commonly used diffusion measures are: (i) fractional anisotropy (FA), which describes the preferred diffusion directionality of water molecules and alterations in the microstructural organisation of the white matter, and (ii) mean diffusivity (MD), which represents the mean magnitude of water diffusivity and reflects tissue density $(12,13)$. In addition, the spatial organisation of white matter fibre bundles (i.e. tract volume) between brain regions can be derived from the directional information of the diffusing water molecules. Note that the intrinsic microstructure (FA and MD) and white matter connectivity measures are not completely independent properties. For example, locally increased FA focuses the directionality of white matter tracts 
and might therefore influence the connectivity. However, because the two concepts describe different aspects of microstructure, it is relevant to report on both.

Previous dMRI studies on type 2 diabetes demonstrated reduced FA and increased MD in different brain regions (14-16) or in white matter tracts connecting frontal, parietal and temporal regions (17). Other type 2 diabetes studies have related increased MD in the parahippocampal gyrus to lower memory performance (18) and reduced FA in the cingulum bundle to higher memory performance (19). To identify microstructural correlates of cognitive decrements, it is important to focus on white matter connectivity because cognitive function depends on the transfer of information between different brain regions via white matter fibre bundles. Besides the commonly used local diffusion measures of specific white matter fibre bundles, it is important to investigate whether white matter connectivity (i.e. total tract volume of white matter fibres) differs and correlates with cognitive performance in type 2 diabetes.

To the best of our knowledge, there are no type 2 diabetes studies that focus specifically on the hippocampus and memory performance using (hippocampal) white matter connections. Therefore, the present study aimed to examine whether hippocampal microstructural abnormalities and white matter connections are related to type 2 diabetes and memory performance.

\section{Materials and methods}

\section{Study population}

Forty-seven participants with type 2 diabetes and 41 participants without type 2 diabetes were recruited from the first 866 participants of The Maastricht Study for additional brain MRI measurements. The Maastricht Study is an ongoing observational prospective population-based cohort study that focuses on the aetiology, pathophysiology, complications and comorbidities of type 2 diabetes. Participants are aged between $40-75$ years and live in the southern part of The Netherlands (20). Participants are considered to have diabetes according to the WHO 2006 criteria if they use diabetes medication, or if they have a fasting blood glucose $\geq 7.0 \mathrm{mmol} / \mathrm{l}$ and/or a 2-h blood glucose $\geq 11.1 \mathrm{mmol} / \mathrm{l}$ after an oral glucose tolerance test. Participants without type 2 diabetes are characterised by fasting blood glucose $<6.1 \mathrm{mmol} / \mathrm{l}$ and a $2-\mathrm{h}$ blood glucose $<7.8 \mathrm{mmol} / \mathrm{l}$. At baseline inclusion, participants underwent an extensive battery of measurements, including cognitive performance tasks, blood pressure measurements and blood sampling. A detailed overview of all procedures is provided in Schram et al. (20). After the baseline measurements of The Maastricht Study, participants were invited to participate in the present MRI study.

Participants with the highest and lowest cognitive scores were selected from the first 866 participants to increase the probability of finding MRI differences associated with cognitive decrements (Table 1). A detailed selection procedure is provided in van Bussel et al. (21). In brief, the division of participants in a low and high cognition group was based on a cumulative score of three neuropsychological tests covering the domains of verbal memory, attention and flexibility, and executive functioning (Table 1). Scores were adjusted for age, sex and education level using linear regression. Exclusion criteria for participants were: (i) a known history of stroke or neurological disease; (ii) a time span between enrollment in The Maastricht Study and MRI > 1.5 years; (iii) incomplete cognitive assessments; (iv) type 1 diabetes mellitus; (v) an impaired fasting blood glucose level, in participants without type 2 diabetes; (vi) mild cognitive impairment or dementia; (vii) the metabolic syndrome; (viii) colour blindness; and (ix) unknown diabetes status. The
Table 1. Characteristics of the Two Cognition Groups. ${ }^{a}$

\begin{tabular}{llll}
\hline & $\begin{array}{l}\text { Lower cognition } \\
(n=40)\end{array}$ & $\begin{array}{l}\text { Higher cognition } \\
(n=38)\end{array}$ & P-value \\
\hline $\begin{array}{l}\text { Type 2 diabetes }(\%, n) \\
\text { Age (years) }\end{array}$ & $55.0(n=22)$ & $47.4(n=18)$ & $0.500^{\mathrm{b}}$ \\
Sex (male, \%, $n)$ & $61.1 \pm 9.5$ & $62.7 \pm 6.7$ & 0.367 \\
Education & $57.5(n=23)$ & $52.6(n=20)$ & $0.666^{\mathrm{b}}$ \\
$\quad$ & & \\
$\quad$ Low $(\%, n)$ & $15.0(n=6)$ & $21.1(n=8)$ & \\
$\quad$ Middle $(\%, n)$ & $47.5(n=19)$ & $42.1(n=16)$ & \\
$\quad$ High $(\%, n)$ & $37.5(n=15)$ & $36.8(n=14)$ & \\
WLT total score & $37.1 \pm 10.0$ & $50.1 \pm 9.0$ & $<0.001$ \\
Stroop (s) & $63.3 \pm 35.2$ & $34.9 \pm 13.1$ & $<0.001$ \\
Verbal fluency & $20.3 \pm 4.9$ & $27.3 \pm 5.7$ & $<0.001$ \\
Cumulative cognition score & $-2.30 \pm 2.18$ & $2.10 \pm 1.25$ & $<0.001$ \\
\hline
\end{tabular}

WLT, (verbal memory) Word Learning Test. ${ }^{a}$ Only participants who were included in the final analysis; independent samples t-test. ${ }^{b}$ Pearson's chi-squared test.

low and high cognition groups were matched on age, sex and education level, and display a similar distribution of participants with and without type 2 diabetes (Table 1).

After taken into account those individuals who declined the invitation and exclusion of participants with MRI contraindications, a total of 47 and 41 participants with and without type 2 diabetes were included, respectively.

Prior to MRI, these participants underwent a general cognitive function test [Mini-Mental State Examination, MMSE (22)] to assess clinically significant differences in cognitive performance compared to the baseline cognitive tests at enrollment in The Maastricht Study. Structural and dMRI brain scans were obtained from all participants. The study was approved by the Medical Ethics Committee of the Maastricht University Medical Center (MUMC+), The Netherlands, and all participants provided their written informed consent. The study is registered at: http://www.clinicaltrials.gov (with identifier NCT01705210).

\section{MRI}

MRI data were acquired on a 3T scanner (Achieva TX; Philips Healthcare, Best, The Netherlands) using a 32-element head coil for parallel imaging. The MRI protocol consisted of structural scans for neuroradiological evaluation [including T1-, T2-, T2*-weighted and fluid attenuated inversion recovery (FLAIR) sequences] and high angular resolution diffusion imaging (HARDI). A three-dimensional T1-weigthed (T1) fast field echo sequence (TR/TE 8.1/3.7 ms, $1.00 \mathrm{~mm}$ isotropic voxel size, 170 continuous slices, matrix size of $240 \times 240 ; 7 \mathrm{~min} 56 \mathrm{~s}$ acquisition time) and FLAIR (TR/TE/TI $4800 / 276 / 1650 \mathrm{~ms}, 1.12 \mathrm{~mm}$ isotropic voxel size, matrix size of $224 \times 224$; 4 min $53 \mathrm{~s}$ acquisition time) were acquired. HARDI data were obtained using an echo-planar imaging (EPI) sequence (TR/TE 6980/84 ms, $2.4 \mathrm{~mm}$ isotropic voxel size, 128 diffusion sensitising gradient directions, a $b$-value of 1500 $\mathrm{s} / \mathrm{mm}^{2} ; 15 \mathrm{~min} 56 \mathrm{~s}$ acquisition time). In addition, a single minimally diffusion-weighted image (b0-scan) was acquired (23).

\section{Data analysis}

The T1 images were automatically segmented to obtain both hippocampal volumes, intracranial volume, subcortical grey matter and the cortical areas using FREESURFER (Martinos Center for Biomedical Imaging, Boston, MA, USA) (24) and the segmentations were inspected visually. dMRI data analysis 
(preprocessing, tractography, connectivity analyses) was performed with the diffusion MR toolbox EXPLOREDTI, version 4.8.2 (25). In brief, the preprocessing steps included: (i) visual image quality assessment; (ii) correction of dMRI images for eddy current induced geometric distortions and head motion; (iii) correction of dMRI images for EPI distortions and transformation to T1 space; and, finally, (iv) estimation of the diffusion tensor for calculating the FA and MD maps.

After preprocessing, the local diffusion measures (FA and MD) were extracted from both hippocampi as derived from FREESURFer. Subsequently, fibre orientation distributions (FOD) were estimated using constrained spherical deconvolution with a maximum harmonic degree of 8 (26), which allows fibre tracking through regions with crossing fibres. The FOD represents the local fibre orientation. Whole brain probabilistic tractography was performed using FOD sampling (27) with a seed point resolution of $1 \mathrm{~mm}^{3}$, a step size of $1 \mathrm{~mm}$, and an FOD and maximum deflection angle threshold of 0.1 and $30^{\circ}$, respectively, yielding approximately 4.3 million streamlines for each dataset. Next, connectivity analysis was performed to obtain white matter tracts (tract volumes) from the individually segmented hippocampi, used as seed region (i.e. include tracts that only go through the hippocampus) to the segmented grey matter. The segmented grey matter was subdivided into five regions: frontal lobe, parietal lobe, temporal lobe, occipital lobe and subcortical grey matter $(28,29)$. Examples of white matter tracts between both hippocampi and the frontal lobe are provided in Fig. 1. Subsequently, the tract volumes seeded from both hippocampi to each region were normalised to the intracranial volume to reduce inter-individual variation (30). A previous study from our group showed that white matter tracts (tract volumes) are reproducible (31). The local diffusion measures (FA and MD) were averaged and tract volumes were added up over the left and right hippocampus, respectively. Tract volumes are interpreted as a measure for connectivity (32).
After careful analyses, data from forty type 2 diabetes participants and 38 participants without type 2 diabetes remained suitable for final analysis. Data from nine participants were excluded as a result of incomplete data $(n=1)$, claustrophobia $(n=2)$, nondiabetes participants with impaired fasting blood glucose levels $(n=2)$, Parkinsonism $(n=1)$, brain injury because of an accident $(n=1)$, an incidental finding (i.e. tumour, $n=1)$ and susceptibility artefacts $(n=2)$.

\section{Cognition}

As described in Schram et al. (20), participants completed an extensive cognitive battery at enrollment in The Maastricht Study. Global cognitive functioning was measured using the MMSE. Verbal memory was assessed by the 15-Word Learning Test (WLT) total score, in which 15 words are presented in five subsequent trials. Immediately after each trail, participants recall as many words as they are able. The maximum score that could be reached, was 75 .

\section{Covariates}

Educational level was assessed by interview and classified into eight levels commonly used in The Netherlands: (1) no education; (2) primary education; (3) lower vocational education; (4) intermediate general secondary education; (5) intermediate vocational education; (6) higher general secondary education; (7) higher vocational education; and (8) university degree. For the present study, educational level was subdivided into three groups: low (level 1-3), middle (level 4-6) and high (level 7-8). Office blood pressure was assessed three times on the right arm after a 10-min rest, using a noninvasive blood pressure monitor (Omron 705IT; Omron, Kyoto, Japan). A
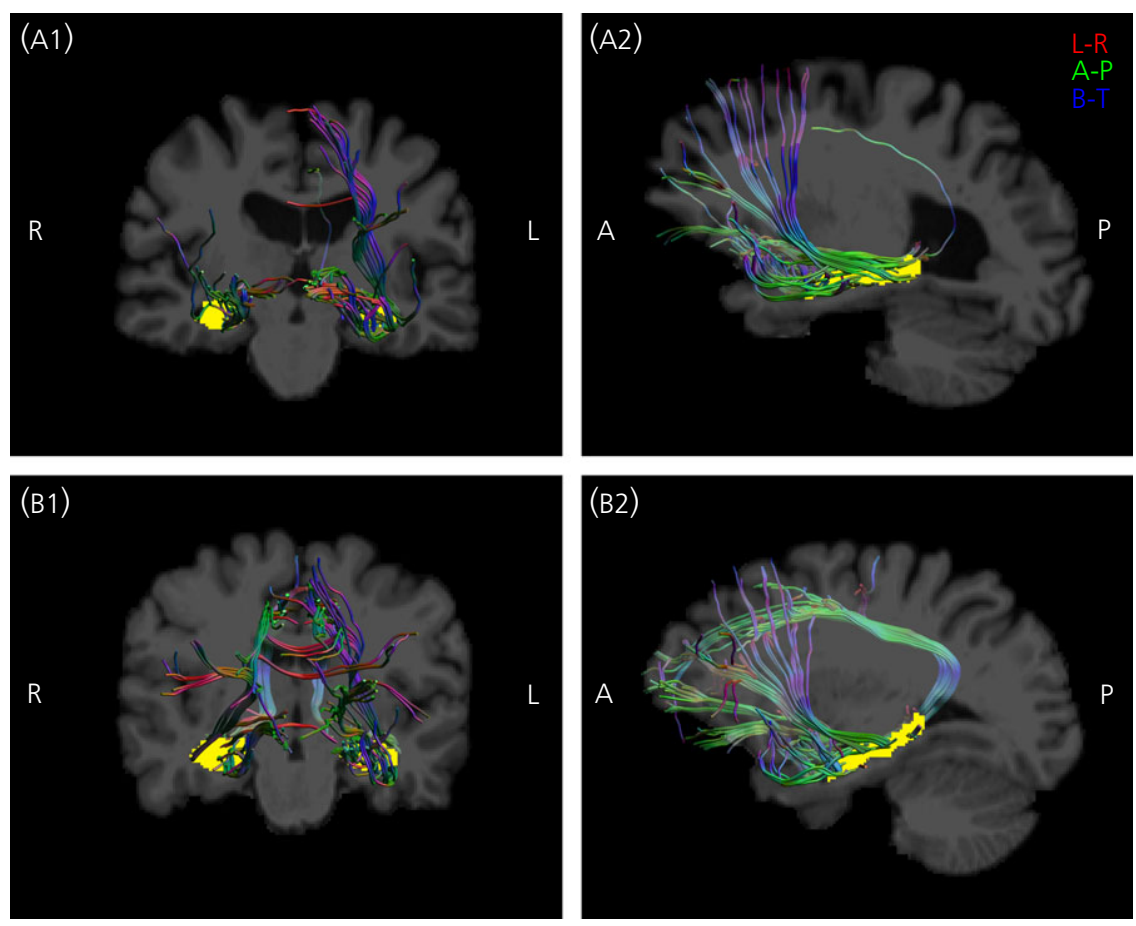

Fig. 1. White matter fibre bundles seeded from both hippocampi (yellow regions of interest) to the frontal lobe of representative participants with (A) and without (B) type 2 diabetes (A1 and B1, coronal view; A2 en B2, sagittal view), projected on a semitransparent T1-weighted image. The colours of the tracts represent the left-right (red), anterior-posterior (green) and bottom-top (blue) directions. Depicted coronal and sagittal levels are purely for illustrative purposes; quantitative analyses was performed independent of the visual presentation selected. 
fourth measurement was performed when the difference between measurement two and three exceeds more than $10 \mathrm{mmHg}$. Here, we used the averaged blood pressure values over all the available measurements (20). White matter lesions were automatically segmented using $\mathrm{T} 1$ and FLAIR in accordance with the method described by de Boer et al. (33).

\section{Statistical analysis}

Descriptive participants' characteristics and diffusion measures are reported as the mean $\pm S D$. Group characteristics were tested using independent samples t-tests and Pearson's chi-squared tests using SPSS, version 20 (IBM Corp., Armonk, NY, USA).

Linear regression analyses, adjusted for age, sex, education level, body mass index, systolic blood pressure, relative (to intracranial) hippocampal volume and relative white matter lesion load to correct for differences in clinical characteristics between groups, were performed to assess the association of the hippocampal diffusion measures ( $F A, M D$ and tract volumes) with type 2 diabetes status and memory performance. In addition, a correction for multiple testing was applied according to Benjamini and Hochberg (34) using a false discovery rate of $10 \%$.

To investigate the combined effect of type 2 diabetes and memory on the diffusion measures, an interaction term between type 2 diabetes and memory performance (WLT total score) was added to the same linear regression model. The use of continuous fasting blood glucose and $\mathrm{HbA}_{1 \mathrm{c}}$ values instead of the dichotomous diabetes status was also tested.

\section{Results}

Table 1 shows the baseline characteristics of the low and high cognition groups because participants were selected based on cognitive status. The groups were matched on age, sex and education and participants with type 2 diabetes were divided equally over the two groups. Table 2 shows the clinical characteristics of participants with type 2 diabetes. Type 2 diabetes participants had higher fasting blood glucose levels, higher $\mathrm{HbA}_{1 c}$ levels, higher body mass index, higher diastolic and systolic blood pressure, and larger white matter lesion loads, compared to healthy controls (Table 2). With respect to cognition, type 2 diabetes participants scored significantly lower on the WLT total score $(P=0.004)$ and on baseline MMSE score $(P=0.008)$ compared to nondiabetes participants. Baseline and repeated MMSE did not differ between participants with and without type 2 diabetes $(P=0.317)$.

For the hippocampus, the local FA was decreased in type 2 diabetes compared to nondiabetes participants $(0.11 \pm 0.01$ and $0.12 \pm 0.02$, respectively; $P=0.033$ ), whereas the $M D$ was increased in type 2 diabetes participants compared to nondiabetes participants $\left(0.98 \pm 0.06\right.$ and $0.93 \pm 0.0510^{-3} \mathrm{~mm}^{2} / \mathrm{s}$, respectively; $P<0.001)$. However, after adjustment for covariates, multivariable linear regression revealed no significant associations between any of the local diffusion measures and type 2 diabetes or memory performance.

Figure 2 shows quantitative boxplots of the relative tract volumes seeded from both hippocampi to the various brain regions. Tract volumes from the hippocampi to the frontal lobe $(P=0.005)$, temporal lobe $(P=0.010)$ and subcortical grey matter $(P=0.031)$ were decreased in type 2 diabetes participants. After adjustment for covariates, multivariable linear regression (Fig. 2 and Table 3) revealed a decreased relative tract volume from the hippocampi to
Table 2. Clinical Characteristics of Participants with Type 2 Diabetes.

\begin{tabular}{|c|c|c|c|}
\hline & $\begin{array}{l}\text { Participants } \\
\text { with } \\
\text { type } 2 \\
\text { diabetes } \\
(n=40)\end{array}$ & $\begin{array}{l}\text { Participants } \\
\text { without type } \\
2 \text { diabetes } \\
(n=38)\end{array}$ & P-value \\
\hline \multicolumn{4}{|l|}{ Type 2 diabetes-related variables } \\
\hline Duration of diabetes (years) & $9.9 \pm 6.8$ & - & \\
\hline Fasting blood glucose (mmol//) & $7.5 \pm 1.2$ & $5.1 \pm 0.3$ & $<0.001$ \\
\hline $\mathrm{HbA}_{1 \mathrm{c}}(\%)$ & $6.7 \pm 0.5$ & $5.6 \pm 0.4$ & $<0.001$ \\
\hline $\mathrm{HbA}_{1 \mathrm{c}}(\mathrm{mmol} / \mathrm{mol})$ & $50.3 \pm 4.9$ & $38.1 \pm 4.4$ & $<0.001$ \\
\hline \multicolumn{4}{|l|}{ Type 2 diabetes medication } \\
\hline None $(\%)$ & 12.5 & 100 & $<0.001^{\mathrm{a}}$ \\
\hline Oral medication $(\%)$ & 75.0 & - & \\
\hline Insulin (\%) & 2.5 & - & \\
\hline Insulin and oral medication (\%) & 10.0 & - & \\
\hline \multicolumn{4}{|l|}{ Clinical variables } \\
\hline BMI $\left(\mathrm{kg} / \mathrm{m}^{2}\right)$ & $29.2 \pm 3.5$ & $24.7 \pm 2.9$ & $<0.001$ \\
\hline $\mathrm{SBP}(\mathrm{mmHg})$ & $152 \pm 18$ & $131 \pm 18$ & $<0.001$ \\
\hline $\mathrm{DBP}(\mathrm{mmHg})$ & $83 \pm 11$ & $76 \pm 13$ & 0.014 \\
\hline White matter lesion volume $\left(\mathrm{cm}^{3}\right)$ & $6.0 \pm 10.5$ & $2.0 \pm 1.5$ & 0.021 \\
\hline Left hippocampal volume $\left(\mathrm{cm}^{3}\right)$ & $3.8 \pm 0.5$ & $4.0 \pm 0.4$ & 0.076 \\
\hline Right hippocampal volume $\left(\mathrm{cm}^{3}\right)$ & $4.0 \pm 0.5$ & $4.1 \pm 0.4$ & 0.332 \\
\hline \multicolumn{4}{|l|}{ Cognitive score } \\
\hline Baseline MMSE total score & $28.6 \pm 1.5$ & $29.4 \pm 0.9$ & 0.008 \\
\hline WLT total score & $39.8 \pm 10.8$ & $47.2 \pm 11.1$ & 0.004 \\
\hline
\end{tabular}

$\mathrm{HbA}_{1 \mathrm{c}}$ glycated haemoglobin; $\mathrm{BMI}$, body mass index; SBP, systolic blood pressure; DBP, diastolic blood pressure; (baseline/repeated) MMSE, (The Maastricht Study/before MRI) Mini-Mental State Examination; WLT, (verbal memory) Word Learning Test. Data are the mean \pm SD. Independent sam-

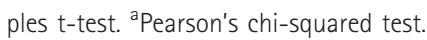

the frontal lobe in type 2 diabetes participants $(P=0.017$, which remains significant after correction for multiple testing). For participants (regardless of type 2 diabetes) who scored lower on memory performance, multivariable linear regression (Table 3) revealed a decreased relative tract volume to the temporal lobe $(P=0.017$, which remains significant after correction for multiple testing).

Additional multivariable linear regression including the interaction term (type 2 diabetes times WLT total score) showed no significant interaction $(P>0.15)$. Analyses with fasting blood glucose levels and $\mathrm{HbA}_{1 \mathrm{c}}$ both showed a trend: high fasting blood glucose levels and high $\mathrm{HbA}_{1 \mathrm{c}}$ levels are associated with a decreased relative tract volume from the hippocampi to the frontal lobe $(P=0.069$ and $P=0.081$, respectively).

\section{Discussion}

The present study investigated whether hippocampal microstructural abnormalities are related to type 2 diabetes and verbal memory. To our knowledge, this is the first study to investigate white matter connections from the hippocampus to different brain lobes in type 2 diabetes. The results of the present study demonstrate fewer white matter connections to the frontal lobe in participants with type 2 diabetes compared to nondiabetic participants. For 
participants who scored relatively low on memory performance, we observed fewer white matter connections to the temporal lobe.

In the present study, participants with type 2 diabetes revealed decreased white matter connections between the hippocampi and the frontal lobe. As a result of decreased white matter connectivity, the white matter appears to be less well organised to transfer and integrate information in participants with type 2 diabetes. Therefore, the affected white matter connectivity, rather than the intrinsic microstructure of the tracts in participants with type 2 diabetes, might underlie the memory decrements. The fact that the frontotemporal connection was affected is in close agreement with the type of cognitive decrements (i.e. memory, executive functioning,

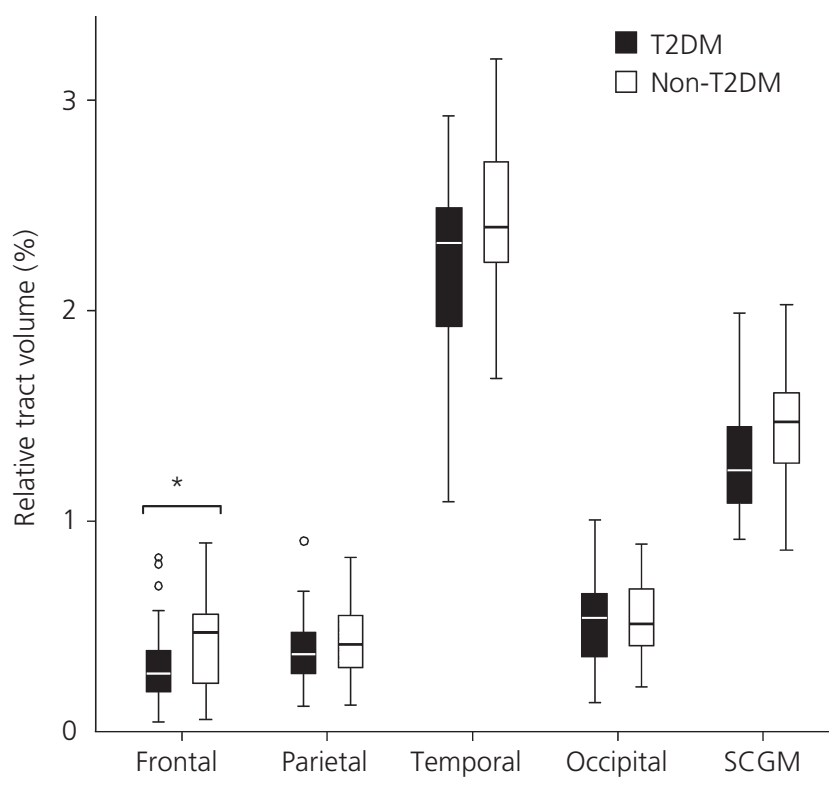

Fig. 2. Boxplots of the relative hippocampal tract volumes to the frontal lobe, parietal lobe, temporal lobe, occipital lobe and subcortical grey matter (SCGM) between participants with and without type 2 diabetes. *Tract volumes were significantly different between groups after multivariable linear regression analysis $(P<0.05)$ (Table 3). T2DM, type 2 diabetes mellitus. processing speed) in type 2 diabetes (8), as well as previous studies reporting frontal and/or temporal structural alterations $(11,35)$.

Only two other studies $(17,19)$ have previously investigated white matter connectivity (tract volumes) in participants with type 2 diabetes and focused, not on the hippocampal, but other white matter tracts (including the superior longitudinal fasciculus and the uncinate fasciculus), for which they did not observe any differences in volume. Hoogenboom et al. (19) related cognitive decline to reduced FA of the uncinate fasciculus bundle. Reijmer et al. (17) showed microstructural abnormalities in specific white matter bundles. Another study by Reijmer et al. (36) observed disruptions of the more global white matter network in patients with type 2 diabetes, which was related to cognitive decline. The decreases in hippocampal white matter connections in type 2 diabetes observed in the present study likely contribute to those global network disruptions.

For participants who scored relatively low on memory performance, we observed fewer hippocampal white matter connections to the temporal lobe. The temporal lobe plays an important role in memory and our results potentially indicate that there is less optimal transfer and integration of information between the hippocampus and the temporal lobe, which could play a role in the underlying memory decrements. The involvement of the temporal lobe in memory performance that we observed is in line with studies by Yau et al. $(18,37)$, who showed that white matter abnormalities in the temporal stem (decreased FA) and parahippocampal gyrus (increased MD) explained the lower memory performance in type 2 diabetes. It was concluded that type 2 diabetes has a deleterious effect on the vulnerability of the temporal lobe memory networks (37), especially the hippocampus and parahippocampal gyrus (18).

The intrinsic microstructure measures (FA and MD) were not different between participants with and without type 2 diabetes or were not associated with memory performance after controlling for the study characteristics. Falvey et al. (15) observed increased MD for type 2 diabetes in both hippocampi after controlling for age, sex and race. When using the same statistical model as Falvey et al.

Table 3. Relationship Between Relative (to Intracranial) White Matter Connections (Tract Volumes) Seeded from Both Hippocampi and Type 2 Diabetes Status and Memory Performance.

\begin{tabular}{|c|c|c|c|c|c|c|}
\hline \multirow[b]{3}{*}{ Relative tract volumes } & \multicolumn{6}{|c|}{ Hippocampus } \\
\hline & \multicolumn{3}{|c|}{ Type 2 diabetes status } & \multicolumn{3}{|c|}{ Memory performance } \\
\hline & $\beta$ & $95 \% \mathrm{Cl}$ & P-value & $\beta$ & $95 \% \mathrm{Cl}$ & P-value \\
\hline To frontal lobe & -0.720 & -1.310 to -0.130 & $0.017^{*}$ & -0.105 & -0.356 to 0.146 & 0.408 \\
\hline To parietal lobe & -0.517 & -1.124 to 0.089 & 0.093 & -0.268 & -0.527 to -0.010 & 0.042 \\
\hline To temporal lobe & 0.118 & -0.332 to 0.567 & 0.603 & 0.235 & 0.043 to 0.427 & $0.017^{*}$ \\
\hline To occipital lobe & 0.022 & -0.549 to 0.594 & 0.938 & -0.137 & -0.380 to 0.107 & 0.267 \\
\hline To SCGM & -0.024 & -0.487 to 0.438 & 0.916 & -0.081 & -0.278 to 0.116 & 0.416 \\
\hline
\end{tabular}

SCGM, subcortical grey matter. Standardised $\beta$ [95\% confidence interval (CI)] indicates increments/decrements of the tract volumes with type 2 diabetes status or memory performance. Model: adjusted for age, sex, education level, body mass index, systolic blood pressure, corresponding relative (to intracranial) hippocampal volume and relative (to intracranial) white matter lesion volume. *Significant after correction for multiple comparisons. 
(15), we observed similar results (i.e. increased hippocampal MD in participants with type 2 diabetes; $P=0.014$ ), which illustrates the importance of the inclusion of clinical characteristics as covariates to prevent superfluous results. Previously, in the same population, we showed an association between increased hippocampal MD and memory performance, but not specifically for type 2 diabetes, for which we found differences in microvasculature (21). In that study, we applied intravoxel incoherent motion imaging, another diffusion technique, which distinguishes water diffusion of the intrinsic microstructure (parenchyma) from that of the microvasculature. Such a distinction cannot be made using standard dMRI. Other studies have also reported local microstructural white matter abnormalities in adolescents with type 2 diabetes (16) and in patients with type 2 diabetes (14); however, these results were not specific to the hippocampus. Other nondiabetic studies, specific to the hippocampus, have shown associations between higher hippocampal MD and memory performance in nondemented participants and in elderly participants with cerebral small vessel disease, respectively $(38,39)$.

In the present study, type 2 diabetes participants scored lower on memory performance and had less hippocampal white matter connectivity to the frontal lobe. However, we did not observe a synergistic effect (interaction) of type 2 diabetes and memory decrements on the white matter connectivity between the hippocampus and frontal lobe. This might be attributable to the relatively healthy diabetes population engaged in the present study, which showed no obvious abnormalities or volume reductions of the hippocampus (Table 2) and was only mildly affected in terms of memory performance, and may be under good treatment control regarding glucose levels. Moreover, the memory scores of participants with type 2 diabetes were in the range of normal performance (40) and hence potentially not sufficiently strong to detect a synergistic effect of type 2 diabetes and memory decrements on the white matter connectivity between the hippocampus and the frontal lobe. In addition, it might be that other connections, either involving the hippocampus or not, are related to memory performance, although these connections were not considered in the present study. The observed effect might therefore represent relatively early signs of developing brain abnormalities related to type 2 diabetes and decrements in cognition.

The strengths of the present study include: first, the extensive characterisation of the participants. Second, both hippocampi that were used as seed for the connectivity analyses and the cortical areas were automatically (and thus operator-independent) parcellated with FREESURFER, which reduces the risk and variability of anatomical misplacements. Third, the scan protocol included high quality structural and dMRI data. The dMRI data were obtained using a high number (128) different gradient directions. Fourth, whole brain tractography yielded approximately 4.3 million tracts, which were used for the connectivity analyses from the hippocampus to the rest of the brain.

A number of issues limit the conclusions. First, the study had a cross-sectional design. Therefore, the results should be interpreted cautiously. Nevertheless, the initial results are promising and open directions for future (longitudinal) studies. Second, the time span between enrollment for The Maastricht Study (i.e. baseline, in which cognitive tests were performed) and the subsequent MRI assessment was $16.4 \pm 3.1$ months, which might have limited the validity of the subject characteristics and the long-term validity of the WLT score at the time of the MRI evaluation. Nevertheless, the baseline and repeated MMSE did not differ, which is indicative of no clinically significant cognitive differences within this time frame. Third, tract volume was used as a measure for white matter connection (32). In theory, alterations in axon diameters or myelination can also lead to differences in tract volume at the same time as maintaining the number of actual connections, although this explanation is less likely. Finally, the present study does not consider specific tracts, such as the cingulum bundle or the uncinate fasciculus $(17,19)$, and therefore cannot provide details of specific effects on these tracts. However, the applied approach, which considers all connections from the hippocampus to other cerebral regions, facilitates a more global assessment of hippocampal connectivity, which might be more sensitive to effects of type 2 diabetes and cognition.

Future longitudinal studies will provide additional insights, favourably including not only participants with type 2 diabetes, but also potentially participants with pre-diabetes, such as the metabolic syndrome or diabetes with mild cognitive impairment. Furthermore, better memory performance in type 2 diabetes has been shown by improvement in fasting plasma glucose levels (41). An important question to be addressed in future (longitudinal) studies is whether improvement in glycaemic control leads to less affected white matter connectivity, and whether specific tracts (e.g. cingulum) are affected. These extensions could clarify whether the decrease in white matter connectivity is possibly an early brain tissue biomarker for verbal memory decrements.

In conclusion, dMRI tractography revealed reduced white matter connectivity between the hippocampus and the frontal lobe in type 2 diabetes. For participants who scored lower on memory performance, tractography revealed reduced white matter connectivity between the hippocampus and the temporal lobe. Memory decrements in participants with type 2 diabetes appear to be associated with altered hippocampal white matter connectivity. The findings of the present study contribute to a better understanding of diabetesassociated memory performance, although the exact mechanism remains to be revealed in future studies.

\section{Acknowledgements}

All of the authors approved the final manuscript submitted for publication. The authors declare that they have no potential conflicts of interest. JFAJ was funded by VENI Research Grant 916.11.059 from The Netherlands Organization for Scientific Research (NWO) and The Netherlands Organization for Health Research and Development (ZonMw). Additionally, this work was supported by 'Stichting de Weijerhorst' foundation. We would like to acknowledge Marc Geerlings and Jos Slenter (Department of Radiology \& Nuclear Medicine, Maastricht University Medical Center, Maastricht, the Netherlands) for continuous hardware and software support. We also would like to acknowledge Alfons Kessels (Clinical Epidemiology and Medical Technology Assessment, Maastricht University Medical Center, Maastricht, the Netherlands) for statistical support. 
Received 22 October 2015, revised 23 December 2015, accepted 14 January 2016

\section{References}

1 van den Berg E, Reijmer YD, de Bresser J, Kessels RP, Kappelle $\sqcup$, Biessels GJ, Utrecht Diabetic Encephalopathy Study G. A 4 year follow-up study of cognitive functioning in patients with type 2 diabetes mellitus. Diabetologia 2010; 53: 58-65.

2 Awad N, Gagnon M, Messier C. The relationship between impaired glucose tolerance, type 2 diabetes, and cognitive function. J Clin Exp Neuropsychol 2004; 26: 1044-1080.

3 Luchsinger JA. Adiposity, hyperinsulinemia, diabetes and Alzheimer's disease: an epidemiological perspective. Eur J Pharmacol 2008; 585: 119129.

4 Kloppenborg RP, van den Berg E, Kappelle $\amalg$, Biessels GJ. Diabetes and other vascular risk factors for dementia: which factor matters most? A systematic review. Eur J Pharmacol 2008; 585: 97-108.

5 Spauwen PJ, Kohler S, Verhey FR, Stehouwer CD, van Boxtel MP. Effects of type 2 diabetes on 12-year cognitive change: results from the Maastricht Aging Study. Diabetes Care 2013; 36: 1554-1561.

6 van den Berg E, Kloppenborg RP, Kessels RP, Kappelle $D_{1}$ Biessels GJ. Type 2 diabetes mellitus, hypertension, dyslipidemia and obesity: a systematic comparison of their impact on cognition. Biochim Biophys Acta 2009; 1792: 470-481.

7 McCrimmon RJ, Ryan CM, Frier BM. Diabetes and cognitive dysfunction. Lancet 2012; 379: 2291-2299.

8 Gold SM, Dziobek I, Sweat V, Tirsi A, Rogers K, Bruehl H, Tsui W, Richardson $S$, Javier $E$, Convit A. Hippocampal damage and memory impairments as possible early brain complications of type 2 diabetes. Diabetologia 2007; 50: 711-719.

9 den Heijer T, Vermeer SE, van Dijk EJ, Prins ND, Koudstaal PJ, Hofman A, Breteler MM. Type 2 diabetes and atrophy of medial temporal lobe structures on brain MRI. Diabetologia 2003; 46: 1604-1610.

10 Hayashi K, Kurioka S, Yamaguchi T, Morita M, Kanazawa I, Takase H, Wada A, Kitagaki H, Nagai A, Bokura H, Yamaguchi S, Sugimoto T. Association of cognitive dysfunction with hippocampal atrophy in elderly Japanese people with type 2 diabetes. Diabetes Res Clin Pract 2011; 94: 180-185.

11 Zhou H, Lu W, Shi Y, Bai F, Chang J, Yuan Y, Teng G, Zhang Z. Impairments in cognition and resting-state connectivity of the hippocampus in elderly subjects with type 2 diabetes. Neurosci Lett 2010; 473: 5-10.

12 Beaulieu C. The basis of anisotropic water diffusion in the nervous system - a technical review. NMR Biomed 2002; 15: 435-455.

13 Eriksson SH, Rugg-Gunn FJ, Symms MR, Barker GJ, Duncan JS. Diffusion tensor imaging in patients with epilepsy and malformations of cortical development. Brain 2001; 124: 617-626.

14 Hsu JL, Chen YL, Leu JG, Jaw FS, Lee CH, Tsai YF, Hsu CY, Bai CH, Leemans A. Microstructural white matter abnormalities in type 2 diabetes mellitus: a diffusion tensor imaging study. Neurolmage 2012; 59: 1098-1105.

15 Falvey CM, Rosano C, Simonsick EM, Harris T, Strotmeyer ES, Satterfield $S$, Yaffe $K$, Health ABCS. Macro- and microstructural magnetic resonance imaging indices associated with diabetes among communitydwelling older adults. Diabetes Care 2013; 36: 677-682.

16 Yau PL, Javier DC, Ryan CM, Tsui WH, Ardekani BA, Ten S, Convit A. Preliminary evidence for brain complications in obese adolescents with type 2 diabetes mellitus. Diabetologia 2010; 53: 2298-2306.

17 Reijmer YD, Brundel M, de Bresser J, Kappelle L, Leemans A, Biessels GJ, Utrecht Vascular Cognitive Impairment Study G. Microstructural white matter abnormalities and cognitive functioning in type 2 diabetes: a diffusion tensor imaging study. Diabetes Care 2013; 36: 137-144.

18 Yau PL, Kluger A, Borod JC, Convit A. Neural substrates of verbal memory impairments in adults with type 2 diabetes mellitus. J Clin Exp Neuropsychol 2014; 36: 74-87.

19 Hoogenboom WS, Marder TJ, Flores VL, Huisman S, Eaton HP, Schneiderman JS, Bolo NR, Simonson DC, Jacobson AM, Kubicki M, Shenton ME, Musen G. Cerebral white matter integrity and resting-state functional connectivity in middle-aged patients with type 2 diabetes. Diabetes 2014; 63: 728-738.

20 Schram MT, Sep SJ, van der Kallen CJ, Dagnelie PC, Koster A, Schaper N, Henry RM, Stehouwer CD. The Maastricht Study: an extensive phenotyping study on determinants of type 2 diabetes, its complications and its comorbidities. Eur J Epidemiol 2014; 29: 439-451.

21 van Bussel FC, Backes WH, Hofman PA, van Oostenbrugge RJ, Kessels $A G$, van Boxtel MP, Schram MT, Stehouwer CD, Wildberger JE, Jansen JF. On the interplay of microvasculature, parenchyma, and memory in type 2 diabetes. Diabetes Care 2015; 38: 876-882.

22 Folstein MF, Folstein SE, McHugh PR. 'Mini-mental state'. A practical method for grading the cognitive state of patients for the clinician. J Psychiatr Res 1975; 12: 189-198.

23 Jones DK. Probabilistic fiber tracking. In: Parker GJM, Jones DK, eds. Diffusion MRI: Theory, Methods, and Applications. Oxford: Oxford University Press, 2011: 396-408.

24 Fischl B, Salat DH, Busa E, Albert M, Dieterich $M$, Haselgrove $C$, van der Kouwe A, Killiany R, Kennedy D, Klaveness $S$, Montillo A, Makris $N$, Rosen B, Dale AM. Whole brain segmentation: automated labeling of neuroanatomical structures in the human brain. Neuron 2002; 33: 341355.

25 Leemans A, Jeurissen B, Sijbers J, Jones D. ExploreDTI: a Graphical Too/box for Processing Analyzing, and Visualizing Diffusion MR Data. In: 17th Annual Meeting of International Society for Magnetic Resonance in Medicine, Hawaii, USA, 2009.

26 Tournier JD, Calamante F, Connelly A. Robust determination of the fibre orientation distribution in diffusion MRI: non-negativity constrained super-resolved spherical deconvolution. Neurolmage 2007; 35: 14591472.

27 Jeurissen B, Leemans A, Jones DK, Tournier JD, Sijbers J. Probabilistic fiber tracking using the residual bootstrap with constrained spherical deconvolution. Hum Brain Mapp 2011; 32: 461-479.

28 Desikan RS, Segonne F, Fischl B, Quinn BT, Dickerson BC, Blacker D, Buckner RL, Dale AM, Maguire RP, Hyman BT, Albert MS, Killiany RJ. An automated labeling system for subdividing the human cerebral cortex on MRI scans into gyral based regions of interest. Neurolmage 2006; 31: 968-980.

29 Cappellani R, Bergsland N, Weinstock-Guttman B, Kennedy C, Carl E, Ramasamy DP, Hagemeier J, Dwyer MG, Patti F, Zivadinov R. Subcortical deep gray matter pathology in patients with multiple sclerosis is associated with white matter lesion burden and atrophy but not with cortical atrophy: a diffusion tensor MRI study. AJNR Am J Neuroradiol 2014; 35: 912-919.

30 Whitwell JL, Crum WR, Watt HC, Fox NC. Normalization of cerebral volumes by use of intracranial volume: implications for longitudinal quantitative MR imaging. AJNR Am J Neuroradiol 2001; 22: 1483-1489.

31 Besseling RM, Jansen JF, Overvliet GM, Vaessen MJ, Braakman HM, Hofman PA, Aldenkamp AP, Backes WH. Tract specific reproducibility of tractography based morphology and diffusion metrics. PLOS ONE 2012; 7: e34125.

32 Vaessen MJ, Jansen JF, Vlooswijk MC, Hofman PA, Majoie HJ, Aldenkamp AP, Backes WH. White matter network abnormalities are associated with cognitive decline in chronic epilepsy. Cereb Cortex 2012; 22: 21392147. 
33 de Boer R, Vrooman HA, van der Lijn F, Vernooij MW, Ikram MA, van der Lugt A, Breteler MM, Niessen WJ. White matter lesion extension to automatic brain tissue segmentation on MRI. Neurolmage 2009; 45: 1151-1161.

34 Benjamini $Y$, Hochberg $Y$. Controlling the false discovery rate: a practical and powerful approach to multiple testing. J R Stat Soc Series B Stat Methodol 1995; 57: 289-300.

35 Garcia-Casares N, Jorge RE, Garcia-Arnes JA, Acion L, Berthier ML, Gonzalez-Alegre P, Nabrozidis A, Gutierrez A, Ariza MJ, Rioja J, GonzalezSantos P. Cognitive dysfunctions in middle-aged type 2 diabetic patients and neuroimaging correlations: a cross-sectional study. J Alzheimers Dis 2014; 42: 1337-1346.

36 Reijmer YD, Leemans A, Brundel M, Kappelle $\sqcup$, Biessels GJ, Utrecht Vascular Cognitive Impairment Study G. Disruption of the cerebral white matter network is related to slowing of information processing speed in patients with type 2 diabetes. Diabetes 2013; 62: 2112-2115.

37 Yau PL, Javier D, Tsui W, Sweat V, Bruehl H, Borod JC, Convit A. Emotional and neutral declarative memory impairments and associated white matter microstructural abnormalities in adults with type 2 diabetes. Psychiatry Res 2009; 174: 223-230.

38 den Heijer T, der Lijn F, Vernooij MW, de Groot M, Koudstaal PJ, der Lugt A, Krestin GP, Hofman A, Niessen WJ, Breteler MM. Structural and diffusion MRI measures of the hippocampus and memory performance. Neurolmage 2012; 63: 1782-1789.

39 van Norden $A G$, de Laat KF, Fick I, van Uden IW, van Oudheusden $\sqcup$, Gons RA, Norris DG, Zwiers MP, Kessels RP, de Leeuw FE. Diffusion tensor imaging of the hippocampus and verbal memory performance: the RUN DMC study. Hum Brain Mapp 2012; 33: 542-551.

40 Van der Elst W, van Boxtel MP, van Breukelen GJ, Jolles J. Rey's verbal learning test: normative data for 1855 healthy participants aged 2481 years and the influence of age, sex, education, and mode of presentation. J Int Neuropsychol Soc 2005; 11: 290-302.

41 Ryan CM, Freed MI, Rood JA, Cobitz AR, Waterhouse BR, Strachan MW. Improving metabolic control leads to better working memory in adults with type 2 diabetes. Diabetes Care 2006; 29: 345-351. 